\section{Utilization of problem-based instructional approach in teaching permutation towards the development of a web-based self-instructional material (WEB-SIM)}

\author{
Lazaro, Bryan Louis G. $\$ \\ Noveleta Senior High School, Philippines (lazarobryanlouis@gmail.com)
}

Received: 30 March 2021

Available Online: 8 June 2021

\author{
Revised: 4 May 2021 \\ DOI: $10.5861 /$ ijrse.2021.621
}

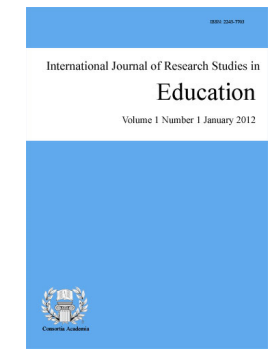

ISSN: 2243-7703 Online ISSN: 2243-7711

OPEN ACCESS

\title{
Abstract
}

This study determined the effectiveness of the problem-solving instructional (PBI) approach on students' problem-solving skills and developed a web-based self-instructional material on permutation. It is based on the Constructivism Theory of Jerome Bruner which basically promotes self-directed learning and collaborative learning process. One hundred thirteen (113) Diliman Preparatory School STEM students served as the respondents of the study. The researcher used both quantitative and qualitative approach in research to answer the specific problems of the study. Pre-Test - Post-Test design was used to find out the effectiveness of PBI approach in enriching permutation problem-solving skills. The respondents were engaged in a focus group interview regarding the challenges they met upon implementation of the approach. Findings show that the students' performance in solving permutation problems is poor before implementing the PBI approach. The PBI approach has three phases identified by the researcher: concept-building, the transformation of teachers' role to facilitator; and promotion of independent learning. With PBI, students were engaged in the learning process. PBI activities let the teachers meet the diverse learners' needs. These activities increase the students' performance in solving the different types of permutation. There are challenges that students and teachers may meet, and there are needs to be addressed upon the implementation of the approach. Proper implementation of the PBI approach will improve the problem-solving skills of the students in permutation. Furthermore, using this study's findings, a web-based self-instructional material (WEB-SIM) was made using a free website builder, "Wix," which can be found on Meet Math mrious17.wixsite.com/meetmath

Keywords: problem-solving skills; problem-based instructional approach; independent learning; web-based self-instructional material; permutation; constructivism; innovation 


\section{Utilization of problem-based instructional approach in teaching permutation towards the development of a web-based self-instructional material (WEB-SIM)}

\section{Introduction}

In a recent study last 2016 of Trends in International Mathematics and Science Study (TIMSS), out of 75 countries joined, Singapore, Hong Kong, and Korea topped the results. Singapore ranked first, claimed that the Mathematics curriculum implemented in their educational system is centered on Mathematical Problem Solving (MPS). Meanwhile, in the same comparative study, the Philippines ranked 35th out of 40 countries participating (Mullis et al., 2004). Researchers enumerated several factors to provide the cause of the implication of the results. One of the leading causes is the mathematics instruction being implemented (Sa'ad et al., 2014). Limjap (2001) explained that the Philippines' mathematics instruction is enclosed with the idea of teaching the common logarithms, providing activities and board work, quizzes and seatwork to attain the mastery level. Achieving the mastery level becomes the ultimate goal of mathematics, whereas students should acquire the conceptual and procedural understanding of mathematical concepts more than any other mechanical skill (Lauritzen,2012). Moreover, students should also indulge in exploring a broad range of problems to develop their analytical skills and their ability to reason in extended chains of argument. It will help students present their analyses straightforwardly and concisely using the language of Mathematics accepted in its community.

Often, when students are stumped on a problem, it is not that the math is complex but that the context may be unfamiliar. A permutation is an excellent example of this phenomenon (Lele, 2011). Students often show a pattern of error in solving word problems regarding this topic. Often, problems come in different types, in various guises. The students must at least know how to deal with these. Researchers introduced several problem-solving techniques for a better understanding of the problem. According to the study conducted by Sukoriyanto et al., (2016) in Universitas Negeri Malang, Indonesia, students' ability to understand the problem, make a problem-solving plan, implement the program, and review the problems given in permutation is low. It is characterized by more than half of students making mistakes in understanding the problems of permutation. Although the students had understood the problem, they had difficulty determining what students should use a formula in planning how to solve the problem. Students also found difficulty when implementing the problem-solving related to the real contexts.

Based on these, the researcher decided to determine the problem-solving instructional approach's effectiveness and developed a web-based self-instructional material on both teachers' and students' permutation. The study results will be a great help to students and educators to provide a better and effective learning acquisition.

\subsection{Statement of the problem}

This study determined the effectiveness of problem-solving instructional (PBI) approach on problem-solving skills of students and developed a web-based self-instructional material on permutation. This research determined students' performance before and after PBI was implemented in three types of permutation problems: linear, circular, and similar things. It also described the step-by-step procedure of the implementation of PBI. Furthermore, this study identified a significant difference in the students' performance before and after the use of PBI in the topics mentioned above in permutation. It also aimed to analyze the challenges encountered by the students and the researcher's observation on the use of the said approach. Upon collecting all the necessary data, a web-based self-instructional material was made from the study results. 


\section{Methodology}

Problem-Based Instruction (PBI) is a student-centered educational strategy. Using this approach, students are progressively given more responsibility for their learning and become responsibly independent of their education teacher. PBI produces independent learners who can continue to learn on their own in life and their chosen careers (Barrows, 2008). This study is anchored on the Constructivism Theory developed by Jerome Bruner. The researcher applied constructivist philosophy to PBI and incorporated the following variables: prior knowledge, quality of problems, tutor performance, group functioning, time spent in individual study, interest in subject matter, and assessment in a model of students' learning. In connection with this, the researcher used the said theory as a guide for the entire learning process. The researcher identified three phases of this approach: (1) concept-building; (2) teachers' role transformation from tutor to being a facilitator; and (3) promotion of independent learning.

The study used the quasi-experimental research design. In this design, the participants' groups will be observed before and after the problem-based learning approach intervention presumed to cause change. Quasi-experimental method is generally used to establish the causality (effect of the independent variable on the dependent variable) in experiments where researchers are not able to randomly assign the subjects to groups or for various reasons; no control group is available for an experimental study (Dinardo, 2008). In this research, the researcher identified the effect of the problem-based learning approach (independent variable) on students' problem-solving skills (dependent variable). Under the said design, the researchers used one group pre-test and post-test design. It is a quasi-experimental research design in which the same dependent variable is measured in one group of participants before and after treatment is administered (Allen, 2019).

The researcher employed mixed methods of research. For the researcher to identify the students' performance before and after implementing the approach and the significant difference between the two implemented tests (Problem nos., 1,3 and 4), the researcher used the quantitative approach in research. According to SIS International Research (2018), Quantitative Research is a structured way of collecting and analyzing data from different sources. It involves the use of statistical, mathematical, and computational tools to derive results. It is conclusive in its purpose as it tries to quantify the problem and understand how prevalent it is by looking for projectable products for a larger population.

On the other hand, to further strengthen the results, the researcher used the qualitative approach to describe PBI as an approach to teaching permutation, the challenges met by students and teachers in using PBI, and the narrative description of the web-based SIM made in PBI format. The researcher also prepared problem-based lesson plans with the given specific objectives before the execution of lessons. The goals were based on Woodcock's (2013) stages of problem-solving to test students' problem-solving skills.

Lessons were taught by the researcher for four (4) consecutive weeks, precisely five times (5) a week. Each class lasted for sixty minutes. This study's respondents are one hundred thirteen (113) STEM students of Diliman Preparatory School assigned to the researcher for the school year 2018-2019. The researcher used non-random sampling since the quasi-experimental design is used. Specifically, the quota sampling technique was used. Involved students were also asked to join the focus group discussion to identify the challenges they met during the approach's implementation.

In conducting this study at the Senior High School Department of Diliman Preparatory School, the researcher widened his boundaries in getting accurate results, but not to the extent of involving other institutions to participate in the experiment. This study also considered the rights of the respondents for confidentiality and anonymity. The researcher secured informed consent for the participants and an approval letter from the principal of the school.

For the researcher to answer the question on the performance level of the students in the pre-test and post-test in terms of the different types of permutation, he used the Likert scale. For Circular Permutation, scores 
from 0-5 will be considered Very Poor, 6-10 is Poor, 11-15 is Fair, 16-20 Good and 21-25 is Very Good. For Linear Permutation, scores from 0-4 will be considered Very Poor, 5-9 is Poor, 10-14 is Fair, 15-19 is Good, and 20-24 is Very Good. However, for Permutation of Similar Things, scores from 0-4 will be considered Very Poor, 5-9 is Poor, 10-13 is Fair, 14-17 is Good, and 18-21 is Very Good.

Mean, percentage, and ranking was employed to analyze responses in the statements and questions in the pre-test and post-test. In addition, these statistical units were used to analyze the results of the Likert Scale. The researcher used Shapiro-Wilk Normality Test to identify if the data gathered are normally distributed. However, to determine the significant differences among the variables with non-parametric properties, Mann-Whitney U was used. Through the use of the XCEL STAT and SPSS, the researcher was able to retrieve absolute data.

\section{Results and discussion}

Problem-Based Instruction (PBI) is an approach in teaching that aims to develop students' problem-solving skills through various heuristics and promote a higher level of thinking skills. PBI involves the presentation of authentic, meaningful situations that serve as foundations for students' investigation. PBI is an excellent approach in teaching permutation and learning as well. The researcher identified three phases of this approach: (1) concept-building; (2) teachers' role transformation from tutor to being a facilitator; and (3) promotion of independent learning. During the first phase, the learners were given a problem activating their prior knowledge. Students were taught some basic knowledge and concepts. According to Subramani (2016), PBI helps create meaning and build personal interpretations of the world based on experiences and interactions. PBI assists in guiding the student from theory to practice during their journey in solving the problem.

During the second phase of the approach, the teacher's role transformed from being a tutor to a facilitator. PBI follows a constructivist perspective in learning as the instructor's role is to guide and challenge the learning process rather than strictly providing knowledge (Subramani, 2016). Students were also given group activities to strengthen their skills in solving problems involving permutation. Online applications such as Kahoot! and Plickers were used to make the learning more engaging on the students' side. From this perspective, feedback and reflection on the learning process and group dynamics are considered essential components of PBI. Students are considered to be active agents who engage in social knowledge construction.

The first two phases served as the foundation of students' problem-solving skills and preparation for the last phase. Online quizzes and seatwork were also given to students, which they will answer individually. This is an excellent technique to promote independent learning. Problems that need high-level thinking skills were given to the students.

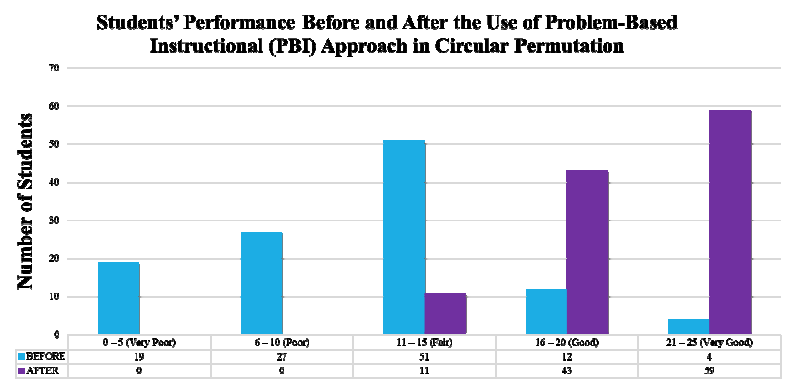

Findings show that of the 113 students, most of the students were rated as very good after the implementation of the approach compared to the respondents' scores in the pre-test. This means that the problem-solving skills of the students for linear permutation were improved. From a fair rating before the implementation, it boosted up as the PBI approach was implemented. The mean grade of the scores also supported these findings.

With a grade mean of 22.97 described as an excellent rating, it can be concluded that the students had increased performance on solving linear permutation word problems after the implementation of the PBI approach. These data also prove that in problem-based instruction (PBI), learners are progressively given more responsibility for their education and become increasingly independent of the teacher for their education. Students learn how to solve the problem using clues, and different heuristics appropriate for the given problem may be individually or collaboratively. Barrows (2008) stated that PBI produces independent learners who can continue to learn on their 
own in life and their chosen careers. Likewise, students' performance after using the problem-based instructional approach in circular permutation produced the same results as the linear permutation.

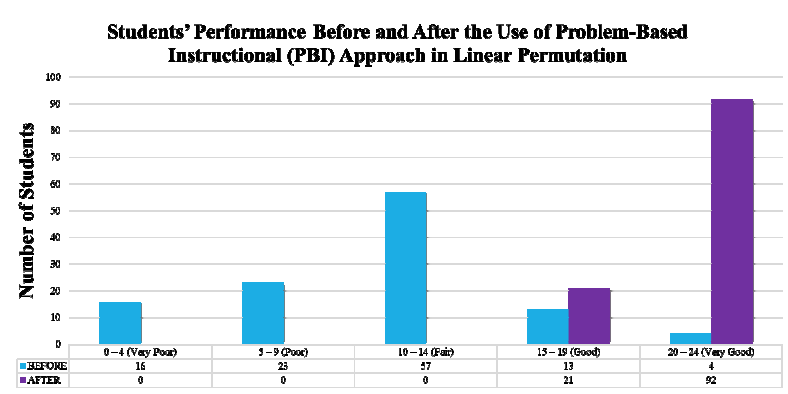

The researcher also tested students' performance before and after using the problem-based instructional (PBI) approach in Circular Permutation. The majority of the population received a very good mark with a mean grade of 21.06, described as a very good rating after the implementation and much higher than the previous. This proves that students became better in problem-solving after the use of the PBI approach in circular permutation. With a mean grade of 21.06 , it can be concluded that the students had increased performance on solving Circular Permutation word problems after the implementation of the PBI approach. The said approach gave the students improved problem-solving skills that helped them answer the post-test items correctly. This data contributes to the proof of the effectiveness of the PBI as an approach in teaching. According to Duch (2001), in addition to course content, PBI can promote critical thinking skills, problem-solving abilities, and communication skills. It can also provide opportunities for working in groups, finding and evaluating research materials, and life-long learning.

The researcher also determined students' performance before and after using the problem-based instructional (PBI) approach in Permutation of Similar Things. Findings show that, like circular and linear permutation results, the majority of the students were graded very well in the given post-test. This means that PBI had helped the students deal with the problem, and the researcher successfully implemented the approach

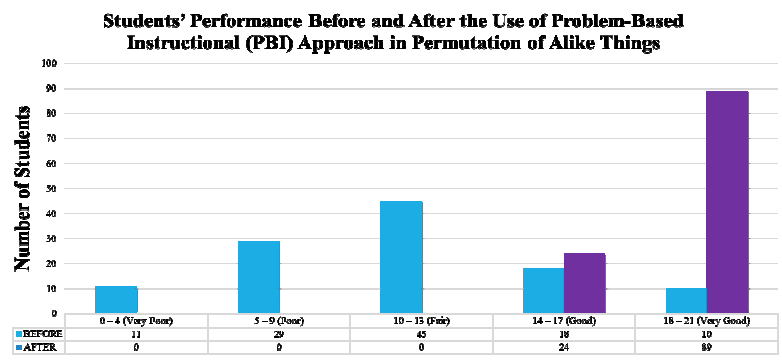
according to the frameworks used in the study. PBI can be incorporated into any learning situation. In the strictest definition of PBI, the approach is used over the entire semester as the primary teaching method. However, broader reports and uses range from including PBI in lab and design classes to using it simply to start a single discussion. PBI can also be used to create assessment items. The main thread connecting these various uses is the real-world problem (Duch et al., 2001). With a grade mean of 18.67 described as an excellent rating, it can be concluded that the students had increased performance on solving Permutation of Alike Things word problems after the implementation of the PBI approach.

To further identify and prove the effectiveness of the PBI approach in teaching permutation, the researcher tested the hypothesis on the significant difference between the pre-test and post-test results of the students.

\begin{tabular}{lccl}
\hline \multicolumn{1}{c}{ Variable } & Z-value & $p$-value & Decision \\
\hline Linear Permutation & -9.178 & 0.00 & Reject Null Hypothesis \\
Circular Permutation & -8.342 & 0.00 & Reject Null Hypothesis \\
Permutation of Alike Things & -8.930 & 0.00 & Reject Null Hypothesis \\
\hline
\end{tabular}

As the data shows, there is a significant difference between the pre-test and post-test of all the topics. Using the findings on the increase in students' performance on solving permutation problems after implementing the PBI approach and hypothesis testing results, the researcher can infer that the approach is significantly practical. The researcher has observed how PBI improved the students' problem-solving skills throughout the PBI approach. Since they were engaged in the learning process and were asked to perform and solve problems individually and collaboratively, they have developed critical thinking skills that led to the improvement of their skills in problem-solving. There may be some pretty tricky problems; students' focus on the matter is strengthened as they progress on PBI phases. 
Barrows (2008) mentioned that PBI emphasizes student-directed learning and the use of knowledge stimulated by the challenge of solving real-world problems in tutor-led small groups. They develop clearly stated solutions that fit the situation and its inherent conditions, based upon information and reasoning to support their arguments. The researcher conducted a focus group discussion to identify the challenges met by students. These are as follows:

Analysis and understanding of the given problem - The students found it difficult to analyze the given problem. They usually find a hard time chunking the word problem and squeezing the clues and variables of it.

A student said, "The challenges I have met in dealing with permutation word problems are determining what type of permutation will be used and the visualization of the word problems. For me, it is a bit hard to solve permutation word problems."

Another student emphasized, "Usually the problem I faced the most is misinterpreting the given word problems and using the wrong formula."

A student also said, "I got confused when I need to analyze the problem whether if it's permutation or combination."

Another student said, "The Permutation Word Problems was one of my weaknesses actually. Math is my greatest fear anyways. It is always confusing me because of counting the letters one by one that makes me mad. Sometimes I always answer these problems after the other questions because I really hate counting them because it makes my eyes hurt because I always count it wrongly and some permutation word problems was hard to understand that I need to read it many times to understand and reach the correct answer because sometimes it makes me (something) more complex or less easy to understand."

Another student said, "Analyzing and manipulating hard problems in dealing with permutation is also a big challenge for me because we certainly need to think outside the box and open our minds to analyze a specific problem."

Failure to comprehend the given problem - Students' poor comprehension skills made the problem more difficult. Some students found it hard to comprehend the problem completely due to words and situations they are not familiar with.

A student answered, "Construction of sentences. I sometimes get confused with how to answer the problems because of how the question was constructed"

Another student added, "Hard to analyze problems. Some words are not in my vocabulary. Some factors are not familiar to me like for example the number of the cards and the "characters" in the card"

A student said, "The challenge that I've met in dealing with Permutation Word Problems is understanding the whole problem. For me, the hardest problem or situation in math is the one with words."

A student said, "Understanding the sentences because if I miss something important about the sentence, I will get the solution wrong."

Tricky situations and conditions for circular and linear permutation problems makes the students confused

The students found it difficult to analyze what kind of permutation are they dealing to and understand the condition given in the problem. A student said, "Some of the items are tricky and hard to answer because you must analyze and think carefully before you solve it."

Another student said, "I got confused when I need to analyze the problem whether if it's permutation or combination. Also, I think I need to practice more in solving permutation especially the tricky questions because

68 Consortia Academia Publishing (A partner of Network of Professional Researchers and Educators) 
I tend to solve it in easy way even though I really don't understand the problem (always). The reason why I got a wrong answer especially in multiple choice, it's because if I got an answer in one of the choices that will be my answer without analyzing the problem."

In PBI, students are required to explore the problem without being 'taught' any contents. They are supposed to 'learn' the content while solving the problem, which unfortunately is a new concept to them (Mansor, et.al, 2015).

Misuse of formula and miscalculations - Student often commit mistakes because of miscalculations. They tend to input wrong variables in their calculator that leads them to wrong answers. They also tend to use the wrong formula since permutations, sometimes, becomes more challenging if the conditions are specified. A student said, "A huge problem of mine is that I get easily confused with number and how I should input them in the calculator. I also had a hard time analyzing the problems."

A student added, "I decided to practice some permutations and combinations problems with the Mathletes. We were able to get most of the answers after some discussion; but the predominant feeling, I think, was that permutations and combinations involve a good deal of "black magic"-that is, we can get the answer, but we don't always know when to multiply, divide, or factorial. That's why I decided I need to write out the steps so that all our Mathletes can refer back to this as a guide for solving permutations and combinations problems."

Also, a student agreed on this and added, "I've tried missed calculation, clicked the wrong number, and mostly, wrong understandings about the problem."

A student also said, "The problems I've met in dealing with permutation word problems were which numbers were placed on the given formula, what number was I supposed to substitute to which letter."

Team members are of different abilities. Some work harder than others - Students often complain about their group mates and the skills they have. Some teammates don't contribute and just wait for the answers of their classmates. Due to the thinking that the task is not equally divided to them, constraints on attention happen leading to the students' inability to solve the problem. Students also questioned the credibility of some peer group members, thus undermining the benefits of collaborative learning. The research team recommended the creation of a strategic system that fosters rigorous learning, promotes peer tutoring and peer assessment, and encourages greater teacher involvement as content expert and guidance to help enhance the level of interpretation (Mansor et.al, 2015).

Some students could not cope with drill and exercises especially additional workloads such as homework Drills and exercises give students the opportunity to master the given problem. In contrary with this, students find it challenging to do their homework independently especially during the first phase of the implementation. Additional workloads done at home affect the students time management, may it be long or short. Most of the short workloads are difficult in nature.

A student said, "Drills and practices help me become comfortable to the topic permutation because of the constant exercises but extra workload/ homework is difficult and tiring."

Another student said, "Extra workloads affect my other subjects. Usually, I have a hard time dealing with time management."

A student also said, "Too much of one thing is bad. I hate doing extra work loads on my rest time because that's the only time I can refresh my mind. One challenge that I usually find difficult is to cope with such exercises."

A student added, "Homework on permutation gives me a hard time because I usually need a person to guide me in doing so."

Focus and attention's span is too little for set of word problems to be solved - One vivid challenge that the 
students faced during the implementation of the approach is their focus on solving problems. Their attention span is too little that it takes them a single minute to be bored. Activities and different strategies are executed to keep them focus.

A student said, "Well, I think my focus is good. I solve problems pretty quick but my attention, I think I am low at that. I get easily distracted especially when I am bored in solving a lot of problems."

Another student said, "If I am able to rate my focus and attention while solving permutation problems, I would give it 5 out of 10 because I get easily distracted. I think that's a challenge for me - to be focused."

A student emphasized, "I can be easily distracted whenever I am solving permutation problems."

A student honestly stated, "The topic is not easy at all because once you've become distracted even just for a second, you may miss some of the important part of the lesson. Because of that, I focus on this subject ten times more compared to other subjects."

Another student said, "I'm a little bit distracted because sometimes, I just couldn't answer the problems. I can focus more on my reviews after the lesson."

Failure to recheck their answers - Students carelessly submit their answers may it be rechecked or not. Students faced this a challenge because most of their incorrect answers are caused by their carelessness or misunderstanding of the problem. Doing the last step in problem-solving which is going back to their answers and revisiting their methods of solving will ensure that their answer is correct.

A student said, "The double checking of answers, after answering a problem, I must be double check it most importantly an answer contains plenty of numbers (big numbers) that make me careless."

A student added, "Sometimes, I get lazy to check if my answer is correct."

A student also added, "I usually regret not checking my answers. If only I did check my answers, then I would be able to understand the problem more."

According to Moldoff (2019), problems and obstacles are not always solved on the first pass, or second or third pass. This is a lot like college transfer. It is a difficult challenge to address from his vantage point. Multiple iterations may be necessary in solving any problem. Testing solutions will often reveal gaps and issues not addressed through review and from various perspectives. One can step back and restart any steps previously mentioned. Solutions can evolve and improve.

Here are the strategies students used to cope with the challenges they met: (1) find key words in the problem; (2) draw a diagram/figure to the solution to better understand the problem; (3) identify the restrictions made in the problem; (4) translate and analyze the word problem carefully; (5) identify all the given; (6) ask some classmates to explain the know-hows of some confusing problems; (7) use of common sense and logic; (8) relate the problems in real-life situations; (9) think deeply; and, (10) find time to practice to master the topic.

There are also challenges in the implementation of this approach met by the researcher, too. The challenges that the researcher met upon the implementation of the approach are the following:

$>\quad$ poor comprehension skills leading to misinterpretation of the word problem. Students commit mistake due to poor comprehension skills.

$>\quad$ students' misinterpretation on the teachers' role transformation (tutor - facilitator - cognitive coach). The facilitator's role of guiding and triggering curiosity, instead of fulfilling the traditional role of content provider may be wrongly perceived by some students as unhelpful and uncommunicative. 
$>\quad$ students' trust and mistrust on group/ peer members that ruins the essence of collaboration and independent learning. Students also questioned the credibility of some peer group members, thus undermining the benefits of collaborative learning. Groups with members of higher academic abilities do relatively better than those whose members are slower academically.

$>\quad$ some students are not prepared to independently work with their own solution. Some students still rely on the teacher's capability to solve the problem. Due to sudden change of roles, the students who are trained in conventional methods find it hard to solve a problem independently.

$>\quad$ time constraints pose a great challenge for the implementation. Preparation for PBI approach consumes time so the teacher must be very flexible and well-equipped with proper skills to cater students' needs and inquiry. Time needed for teacher supervision and advice to individuals or groups is much greater than that required in conventional teaching.

$>\quad$ some students are also not resourceful in searching for information, accustomed to the spoon-feeding method of learning. Most of the students are trained in the teacher-directed way of learning. Due to this fact, they tend to just wait for the information to be echoed to them with the proper step-by-step procedure.

$>\quad$ dealing with students' attitudes will test teacher's patience. Consistent support needs to be given to all students so that they will never stop trying to succeed. Various strategies need to be arranged and executed, such as directing students' focus towards problems in the basic or elementary category first, or problems under certain topics that are less challenging.
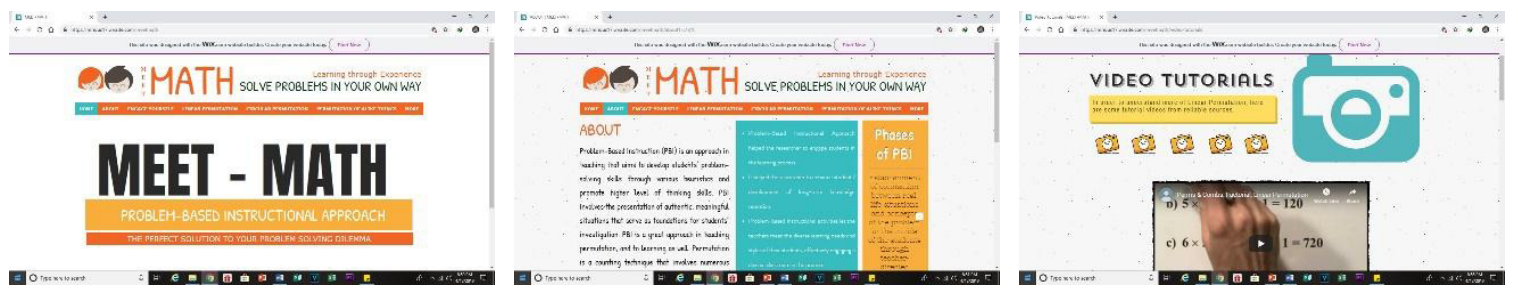

Desktop View of the Website

To cope with the latest technology trend, the researcher made a web-based self-instructional material (SIM) through Wix.com, a free website-builder available on all internet platforms. This web-based SIM will be a great help for the teachers, as well as for students. The site's name is Meet Math and can be found on https://mrious17.wixsite.com/meetmath. It has seven (7) different tabs: Home, About, Engage Yourself, Linear Permutation, Circular Permutation, Permutation of Alike Things, Last Hurrah, and Feedback tabs. Under the Home Tab, the user will see the site's name and its description. The server will also inform the user of the instructional approach used for the entire website.

On the other hand, in the About tab, the website will notify the user of the Problem-Based Instructional approach according to the researcher's summary and findings. The user will also know the phases that he/she must undergo to attain a higher level of thinking and problem-solving skills are. It is essential to understand their stages, for they need to establish a mindset of independent learning. Engage Yourself tab contains the pre-test on permutation. This tab is made to test the user's previous knowledge about the topic and the current level of his/her problem-solving skills. The user will not be able to access the following tabs if he/she fails to answer the pre-test. Once the user submits his/her answer, a code will be given to him/her as access to the following tabs.

The following three tabs are the sub-lessons under permutation: Linear Permutation, Circular Permutation, 
and Permutation of Alike Things. Under these tabs are Definition and Concepts, Video Tutorials, Drills and Practices, Exercises, and Checkpoint. Under the Definition and Concepts sub-tab, the meaning and formula of each type of permutation are introduced. The next sub-tab, Video Tutorials, contains videos of exercises and drills for the topic being discussed. These videos were all filtered according to their usefulness and reliability on the subject. This tab will enable the user to learn the case independently. The third sub-tab is the Drills and Practices, where the user can deal with interactive exercises with immediate response for the correct answer.

Similarly, the user can find more exercises on the fourth sub-tab, which is Exercises. The researcher separately made these two tabs to ensure that the user is already equipped with proper knowledge before proceeding to the last sub-tab, the Checkpoint. In this tab, the user will encounter a series of word problems testing the knowledge he/she acquired independently. Once he/she finishes answering the given problems and successfully submitted his/her forms, codes for the following tabs will be given to him/her.

The Last Hurrah is one of the primary tabs of this website and second to the last in arrangement but one of the website's essential parts. This contains

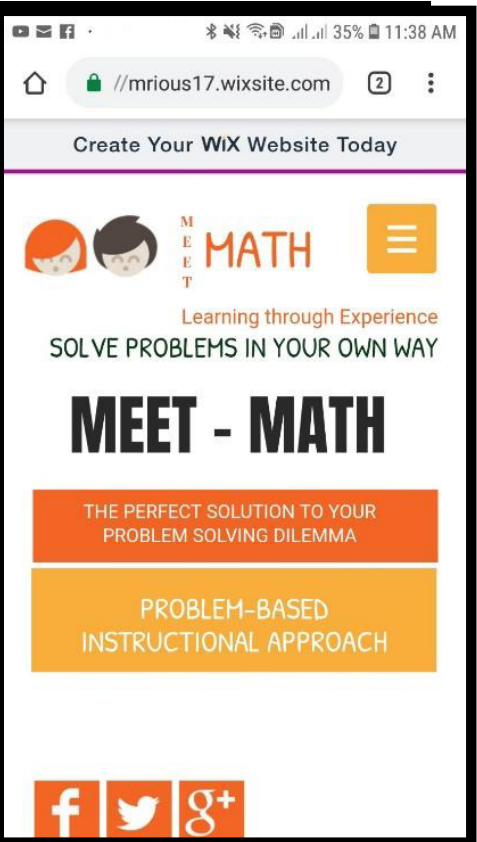

Mobile View of the Website the post-test for the user's overall performance from his/her learnings on the previous tabs. Lastly, the Feedback form will allow the user to offer some suggestions that he/she thinks might improve the site or the matters he/she is confused with. This will help make the website more interactive, flexible, and user-friendly to the users.

Using the gathered data, it can be concluded that:

$>$ Students' performance in solving problems on permutation before the implementation of PBI approach is poor.

Problem-Based Instructional (PBI) approach helps to engage students in the learning process.

> Problem-based Instructional activities let the teachers meet the diverse learning needs and styles of their students, effectively engaging a diverse classroom in the process.

$>$ It also increases the students' performance in solving the different types of permutation. There are challenges that students and teachers may meet and have to be addressed upon the implementation of the approach.

$>$ Proper implementation of the PBI approach will improve the problem-solving skills of the students in permutation. A web-based self-instructional material (SIM) can be used in implementing PBI approach.

$>$ The site's name is Meet Math and can be found at https://mrious17.wixsite.com/meetmath.

In view of the findings and conclusions made, the researcher has drawn out the following recommendations: Mathematics educators should use the PBI approach in teaching permutation. School administrators must review the different processes and phases in implementing PBI approach. Mathematics educators should continue using the PBI approach for it poses a significant effect on the students' performance in solving word problems involving permutation. Educators should use the PBI approach in other topics and even in other subjects. Curriculum developers should address the different challenges met during the implementation of the approach by designing strategies for the learning to be more meaningful. Future researchers and all educators should consider the use of the PBI-themed web-based self-instructional material in solving problems of permutation. 


\section{References}

Abrahamson, D. (2008). Fostering the emergence of an embodied cognitive artifact: The case of the line in a design for probability. In D. Abrahamson (Chair), D. Earnest (Organizer), and H. Bass (discussants), AERA 2008 Symposium: The many values of the number line.

Allen, M. (2017). One-group pretest-posttest design. The SAGE encyclopedia of communication research methods. Sage. https://doi.org/10.4135/9781483381411.n388

Barrows, H. (2008). Problem-based instruction (PBI). Retrieved from http://web.cortland.edu/frieda/id/IDtheories/46.html

Barrows, H. S. (2008). A specific problem-based, self-directed learning method designed to teach medical problem-solving skills, and enhance knowledge retention and recall. In H.G. Schmidt \& M. L. De Volder, (Eds.), Tutorials in problem-based learning: A new direction in teaching the health professions (pp. 16-32). Maastricht: Van Gorcum.

Baskarada, S. (2014). Qualitative case study guidelines. The Qualitative Report, 19(40), 1-18. https://doi.org/10.46743/2160-3715/2014.1008

Brunner, J. (2007). Constructivist learning theory. Retrieved from http://tip.psychology.org/bruner.html

Carney, L. (2018). The 10 best free website builders in 2018. Retrieved from https://www.websitebuilderexpert.com/website-builders/best/free/

Dinardo J. (2010) Natural experiments and quasi-natural experiments. In S. N. Durlauf \& L. E. Blume (Eds.) Microeconometrics (pp. 139-153). Palgrave Macmillan. https://doi.org/10.1057/9780230280816_18

Duch, B. J., Groh, S. E, \& Allen, D. E. (Eds.). (2009). The power of problem-based learning. Sterling, VA: Stylus.

Esparrago, M. (2016). Next century mathematics grade 10. Counting techniques and probability. Phoenix Publishing House.

Harris, J., \& Al-Bataineh, M. (2016). One to one technology and its effect on student academic achievement and motivation. Contemporary educational technology, 7(4), 368-381. https://doi.org/10.30935/cedtech/6182

Higgins, S. (2012). The impact of digital technology on learning: A summary for the education endowment foundation. Durham University.

Jitendra, A. K. (2007). Solving math word problems: Teaching students with learning disabilities using schema-based instruction. Austin, TX: Pro-Ed.

Kaufman, C., Perlman, R., \& Speciner, M. (2008). Network security: Private communication in a public world (2nd ed.). Upper Saddle River, NJ, Prentice Hall.

Lauritzen, P. (2012). Dissertations in education, humanities, and theology. Conceptual and procedural knowledge of mathematical functions. Joensuu: Publications of University of Eastern Finland.

Lele, C. (2011). The difficulty of context: Combinations and permutations questions. Retrieved from https://magoosh.com/gre/2011/the-difficulty-of-context-combinations-and-permutations-questions/

Limjap, A. (2001). Individual and social aspects of learning: Developing framework for a deeper understanding of school mathematics in the Philippines. Sangguni Centennial Issue, xii(1), 65.

Linesronda, J. (2012). K-12 math problems. Linear vs circular permutations. Retrieved from https://math-problems.math4teaching.com/linear-vs-circular-permutations/

Mansor, A. N., Abdullah, N. O., Wahab, J. A., Rasul, M. S., Nor, M. Y., Nor, N. M., \& Raof, R. A. (2015). Managing problem-based learning: Challenges and solutions for educational practice. Asian Social Science, 11(4). https://doi.org/10.5539/ass.v11n4p259

Mullis, I. V., Martin, M. O., Gonzales, E. J., \& Chrostowski, S. J. (2004). TIMMS 2003 International Mathematics Report. IEA.

Sa'ad, T. U., Adamu, A., \& Sadiq, A. M. (2014). The causes of poor performance in mathematics among public senior secondary school students in Azare Metropolis of Bauchi State, Nigeria. IOSR Journal of Research and Method in Education, 4(6), 32-40. https://doi.org/10.9790/7388-04633240

SIS International Research (2018). What is quantitative research. Retrieved from https://www.sisinternational.com/what-is-quantitative-research/

Subramani, D. P. (2016). New trends in education. Lulu Publication. 
Lazaro, B. L. G.

Sukoriyanto, S., Nusantara, T., Subanji, S., \& Chandra, T.D. (2016). Students' thinking process in solving combination problems considered from assimilation and accommodation framework. https://doi.org/10.5897/ERR2016.2811

Sukoriyanto, S., Subanji, S., Nusantara, T., \& Chandra, T. (2016). Students' errors in solving the permutation and combination problems based on problem solving steps of Polya. International Education Studies, 9(2). https://doi.org/10.5539/ies.v9n2p11

TIMSS and PIRLS. (2016). IEA's Trends in International Mathematics and Science Study. Retrieved from https://timss2015.org/download-center

Woodcock, J. (2013). Five stages of problem-solving. Institute of Development Studies Bulletin 25(2), 1-13.

74 Consortia Academia Publishing (A partner of Network of Professional Researchers and Educators) 